\title{
The Alaska Earthquake of 1964 : Radiation of Long-Period Surface Waves and Source Mechanism
}

\author{
Hiroo Kanamori ${ }^{1}$ \\ Department of Earth and Planetary Sciences \\ Massachuselts Institute of Technology \\ Cambridge, Massachusetts 02139
}

\begin{abstract}
The records of multiple Love and Rayleigh waves of the Alaska earthquake of 1964 were recovered from the 30-100 seismograph records at the WWSSN stations. The seismograms were equalized to a propagation distance of $9 \pi / 2$ (equivalent to G5 and R5 at $\Delta=\pi / 2$ ). These seismograms were compared with synthetic seismograms for radiation pattern and amplitude to estimate various source parameters. The synthetic seismograms were computed from the normal mode solutions. One simple, yet plausible, source model was found. The nature of the fault is essentially that of a low-angle thrust faulting. The direction of rupture propagation does not coincide with the strike of the fault. This enables one to distinguish between the fault plane and the auxiliary plane. The source parameters determined are as follows: force system. double couple, reverse dip slip; fault plane, dip angle $20^{\circ}$, dip direction $\mathrm{N} 24^{\circ} \mathrm{W}$; rupture length, $600 \mathrm{~km}$; rupture velocity, $3.5 \mathrm{~km} / \mathrm{soc}$ towards $\mathrm{S} 25^{\circ} \mathrm{W}$; moment, $7.5 \times 10^{20}$ dyne-cm; average slip dislocation, 7 meters in $\mathrm{N} 24^{\circ} \mathrm{W}$ direction; stress drop, 28 bars; strain drop, $0.4 \times 10^{-4}$; released strain energy, $1.5 \times 10^{25}$ ergs. The moment and the width of the fault plane of this earthquake are much larger than those of any other earthquakes reported.
\end{abstract}

The Prince William Sound, Alaska, earthquake of March 28, 1964, is one of the largest earthquakes in history. Despite its tectonic importance, however, considerable ambiguity still exists concerning the nature of the faulting. This is clearly due to the lack of reliable seismological data, particularly $S$-wave and surfacewave data.

The debate about the source mechanism of this earthquake is well-known. Algermissen [1966] who used $P$-wave data, suggested that it is a predominantly normal fault along a steeply dipping plane. Press and Jackson [1965], and Press [1965], showed that the surface deformation can be explained in terms of a nearly. vertical fault extending to a depth of 100-200 $\mathrm{km}$. On the other hand, Plafker [1965] proposed on the basis of the tectonic deformations associated with this earthquake that the source of this earthquake is a low-angle thrust fault. Savage and Hastie [1966] advocated Plafker's interpretation. Stauder and Bollinger [1966]

1 On leave from Earthquake Research Institute. University of Tokyo, Japan.

Copyright (c) 1970 by the American Geophysical Union also preferred this interpretation from considerations of the source mechanisms of the preshocks and aftershocks, togethe with the long-period $P$-wave data. Recently, Harding and Algermissen [1969], using $S$-wave polarization data from the low-magnification seismograms, proposed predominantly strike-slip faulting (doublecouple). Toksöz et al. [1965] used long-period surface waves obtained at several stations; they found that a double-couple source with both strike-slip and dip-slip motions on a steeply dipping plane can explain the surface-wave data. The fault length and the rupture velocity were estimated to be $600 \mathrm{~km}$ and $3 \mathrm{~km} / \mathrm{sec}$ (in $\mathrm{S} 50^{\circ} \mathrm{W}$ direction), respectively.

Stimulated by these discussions, we made a thorough survey of the standard 30-100 longperiod seismograms obtained at the WWSSN stations. It was found that the seismograms from some of these stations show recoverable, though complicated, multiple surface waves with large amplitude. In the hope of obtaining a new set of data to resolve the nature of the faulting, considerable effort was made to recover multiple surface waves from as many stations as possible. This paper presents those records in an equalized form, and interprets them, on the 


\section{HIROO KANAMORI}

TABLE 1. Station Data for the Alaska Earthquake of March 28, 1964

(Origin time, $3 \mathrm{~h} 36 \mathrm{~m} 13.0 \mathrm{~s}$; latitude, $61.1^{\circ} \mathrm{N}$; longitude, $147.6^{\circ} \mathrm{W}$; depth, $33 \mathrm{~km} ; M_{\mathrm{a}}=8.5$ )

\begin{tabular}{|c|c|c|c|c|c|c|c|c|}
\hline Station & $\begin{array}{c}\Delta, \\
\operatorname{deg}\end{array}$ & $\stackrel{l}{l,}$ & $\underset{\mathrm{km}}{l+L,}$ & $\begin{array}{c}\phi_{1} \\
\mathbf{d e g}\end{array}$ & $\begin{array}{l}\phi^{\prime}, \\
\text { deg }\end{array}$ & Component & Phase & Magnification \\
\hline ADE & 112.739 & 12540.4 & 40020.6 & 238.7 & 30.4 & UD, EW & $\mathrm{R4}, \mathrm{R} 5, \mathrm{G} 5, \mathrm{G} 6$ & 750 \\
\hline AFI & 77.194 & 8586.8 & 40011.7 & 204.1 & 11.8 & UD, EW & R5, G4, G5 & 750 \\
\hline ARE & 97.712 & 10867.7 & 40023.1 & 110.0 & 331.6 & EW & G5, G6 & 1500 \\
\hline BAG & 76.670 & 8520.5 & 40024.5 & 279.7 & 29.9 & EW & G5, G6 & 1500 \\
\hline CHG & 84.444 & 9382.0 & 40021.2 & 299.1 & 26.6 & UD & R6 & 3000 \\
\hline $\mathrm{COP}$ & 62.506 & 6936.5 & 40009.8 & 12.6 & 349.2 & UD, EW & R4, R5, G4, G5 & 375 \\
\hline GDH & 36.452 & 4045.4 & 40014.8 & 36.8 & 305.4 & NS & G4, G5 & 750 \\
\hline GEO & 47.707 & 5299.0 & 40024.8 & 84.1 & 321.7 & NS & G4, G5 & 350 \\
\hline HKC & 74.612 & 8289.9 & 40023.4 & 288.1 & 29.9 & UD & R5 & 750 \\
\hline HNR & 81.381 & 9051.5 & 40019.0 & 232.3 & 22.9 & UD & R5 & 1500 \\
\hline $\mathrm{KEV}$ & 49.385 & 5479.6 & 40009.1 & 2.5 & 356.6 & UD & R5, R6 & 750 \\
\hline $\mathrm{LAH}$ & 81.578 & 9058.5 & 40014.4 & 324.8 & 19.2 & UD, EW & $\mathrm{R} 5, \mathrm{R6}, \mathrm{G4}, \mathrm{G5}$ & 750 \\
\hline LPS & 62.554 & 6953.7 & 40022.8 & 111.4 & 332.2 & UD & R5 & 750 \\
\hline MAN & 77.932 & 8661.2 & 40024.6 & 278.3 & 29.8 & UD & R4, R5 & 750 \\
\hline MUN & 119.648 & 13307.6 & 40024.3 & 258.8 & 33.8 & UD, EW & $\mathrm{R} 4, \mathrm{R} 5, \mathrm{G} 5, \mathrm{G} 6$ & 750 \\
\hline NAI & 120.238 & 13358.1 & 40009.2 & 354.9 & 2.5 & UD, EW & R5, R6, G5, G6 & 1500 \\
\hline PDA & 70.795 & 7860.8 & 40017.1 & 45.4 & 334.1 & UD & R5 & 750 \\
\hline RIV & 106.840 & 11884.6 & 40018.3 & 229.7 & 26.4 & EW & G4, G5 & 750 \\
\hline SHI & 87.901 & 9759.6 & 40010.5 & 342.3 & 9.8 & UD, EW & R5, R6, G5, G6 & 1500 \\
\hline
\end{tabular}

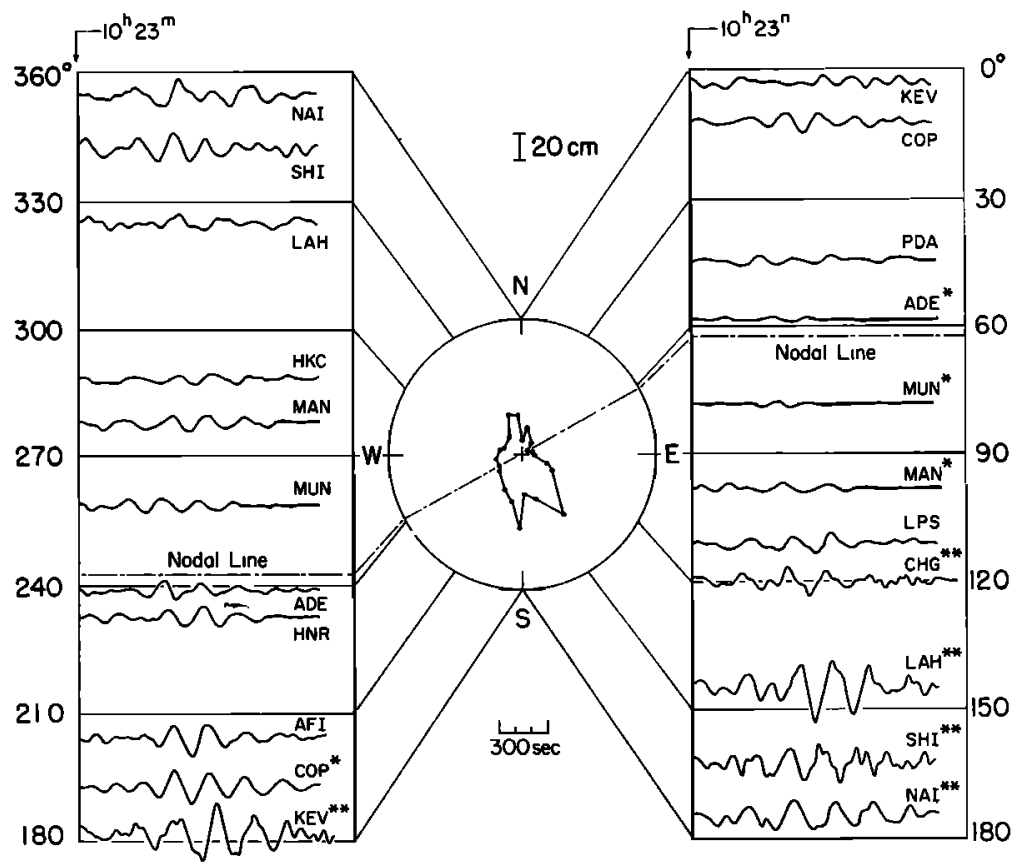

Fig. 1. Rayleigh waves (R5) equalized to a propagation distance of $9 \pi / 2$, Alaska earthquake of March 28, 1964. The vertical scale gives the amplitude on the standard 30-100 seismogram with a magnification of 1500 . Upward motion on the trace shows upward ground motion. For stations without asterisk, the equalization is made for R5; for those with an asterisk or with two asterisks, the equalization is made for R4 and R6, respectively. The nodal lines for the model shown in Figure 5B are shown. 
basis of synthetic seismograms, to determine various source parameters. A method similar to that used by Kanamori [1970] is employed.

\section{Data}

Actual-size copies of the long-period seismograms from WWSSN stations were collected. Although the traces are usually entangled because of the excessively large amplitude, it was possible to recover many multiple surface-wave trains such as R4, R5, R6, G4, G5, G6, etc. Table 1 lists the data used here. Rayleigh waves were windowed, between group velocities 3.47 and $3.75 \mathrm{~km} / \mathrm{sec}$, from vertical components; Love waves were windowed from horizontal components between group velocities 4.3 and 4.5 $\mathrm{km} / \mathrm{sec}$. The traces were digitized at every 4 sec and equalized to a magnification of 1500 , and to a propagation distance of $9 \pi / 2$. The latter equalization, which involves geometrical spreading, attenuation, and the phase shift due to propagation, was made as follows.

We let $U(\Delta, \omega)$ be the complex spectrum of the seismogram at a station of propagation distance $\Delta$. The equalized seismograms at a distance $\Delta_{0}$ (here $\Delta_{0}=9 \pi / 2$ ) as a function of time can then be written as

$$
\begin{array}{r}
u\left(\Delta_{0}, t\right)=\left(\left|\frac{\sin \Delta}{\sin \Delta_{0}}\right|\right)^{1 / 2} \int_{-\infty}^{+\infty} U(\Delta, \omega) \\
\cdot \exp \left\{i\left[\omega \frac{\Delta-\Delta_{0}}{C}-\frac{\pi}{2} M\right]\right\} \\
\cdot \exp \left[k^{*}\left(\Delta-\Delta_{0}\right)\right] \exp (i \omega t) d \omega
\end{array}
$$

where $C$ and $k^{*}$ are phase velocity and attenuation coefficient as a function of frequency, re-

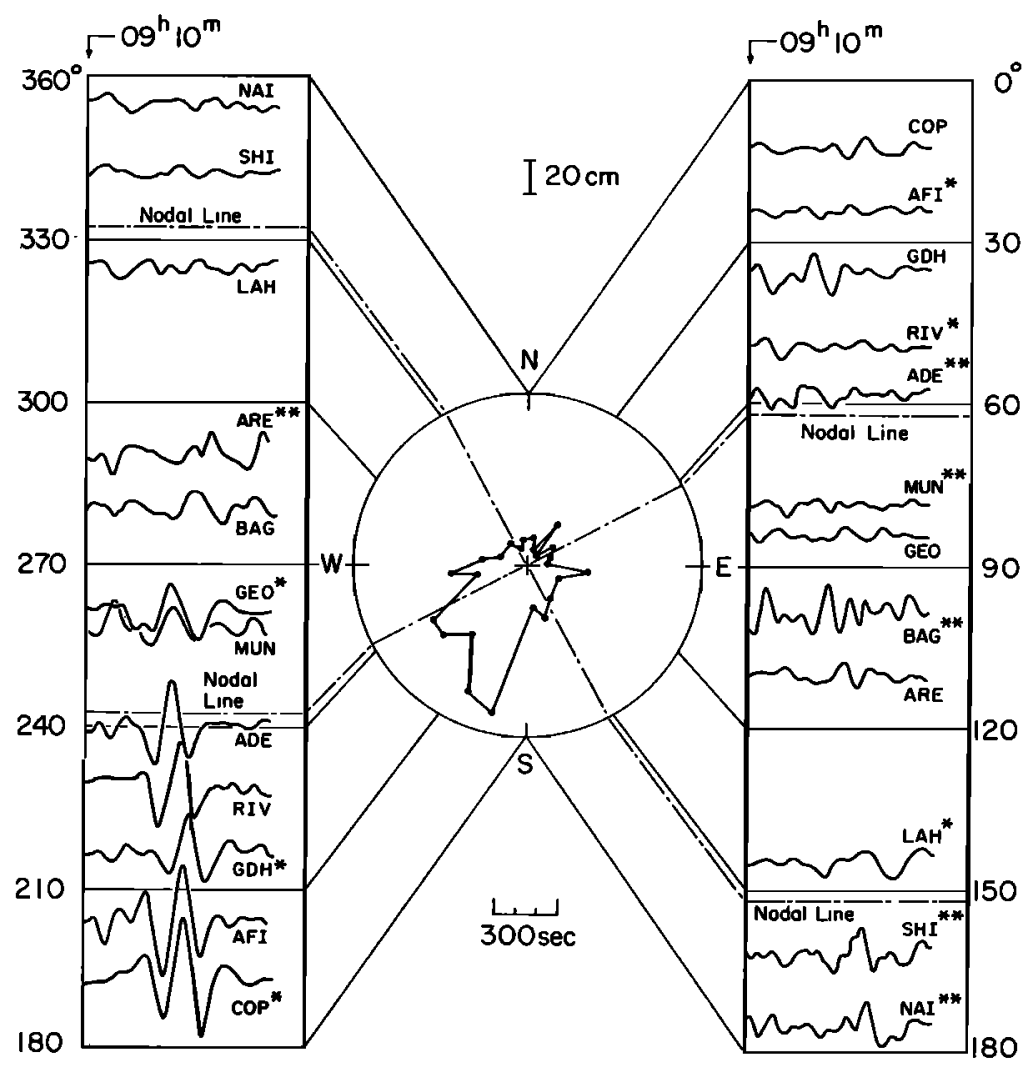

Fig. 2. Love waves (G5) equalized to a propagation distance of $9 \pi / 2$, Alaska earthquake of March 28, 1964. The vertical seale gives the amplitude on the standard 30-100 seismogram with a magnification of $\mathbf{1 5 0 0}$. The counter-clockwise motion around the epicenter is taken upward on the trace. For stations without asterisk, the equalization is made for G5. For those with an asterisk or with two asterisks, the equalization is made for G4 and G6, respectively. The nodal lines for the model shown in Figure $5 \mathrm{~B}$ are shown. 
spectively. For $C$ and $k^{*}$, the values listed in Tables 2 and 3 of Kanamori [1970] were used. The integer $M$ is the number of polar or antipolar passages in going from $\Delta_{0}$ to $\Delta$.

The equalized seismograms thus obtained are shown in Figures 1 and 2. These traces correspond to R5 and G5 that would have been observed if the stations with the standard 30100 seismograph having a magnification of 1500 were located at a distance of $\pi / 2$. The circular plots at the center show the radiation patterns of the maximum trace amplitude. The important features of these seismograms are: (1) the maximum amplitude of Love waves is considerably larger than that of Rayleigh waves; (2) for both Love and Rayleigh waves, the radiation is nearly one-lobed; (3) the azimuth of the lobe of Love waves does not coincide with that of Rayleigh waves: the difference is about $45^{\circ}$.

\section{INTERPRETATION}

For interpretation, we shall make extensive use of the synthetic seismograms of surface waves calculated by the method described by Kanamori [1970]. Since the focus of the main shock is considered to be shallow [Sherburne et al., 1969] we first place a point source at a depth of $33 \mathrm{~km}$ in computing the synthetic seismograms.

Radiation pattern. The radiation pattern is determined by the force geometry of the source and the source dimension; the former determines the lobe pattern and the latter the asymmetry. Usually a crude guess of the force geometry can be made from the observed lobe pattern. For this great earthquake, however, the lobe pattern is too obscured because of so large an asymmetry for the force geometry to be recoverable. We shall therefore combine the bodywave data to construct a source model.

Most reliable body-wave data so far obtained are the first-motion data of $P$ waves. One of the nodal planes has been determined very well; it has a dip angle between $82^{\circ} \mathrm{SE}$ and $87^{\circ} \mathrm{NW}$, and a strike between $\mathrm{N} 66^{\circ} \mathrm{E}$ and $\mathrm{N} 40^{\circ} \mathrm{E}$ [Harding and Algermissen, 1969; Stauder and Bollinger, 1966] (see Figure 3). Because of the unfavorable distribution of the stations, the second nodal plane has not been determined. We shall therefore take the following procedure for interpreting the surface-wave data. We fix the

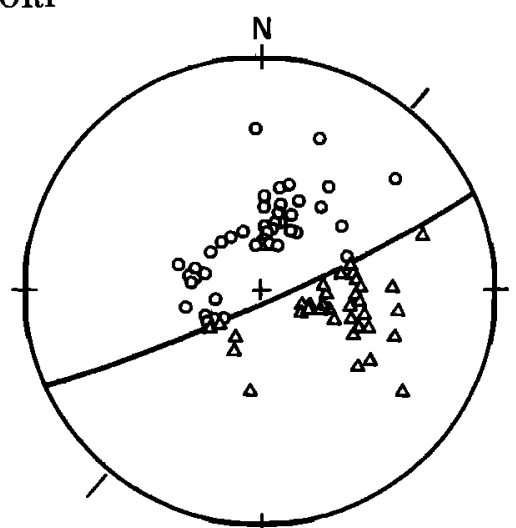

Fig. 3. Equal-area projection of the focal mechanism solution based on the first motion of $P$ waves. Circles indicate compression and triangles indicate rarefaction. The nodal plane has a strike azimuth of $\mathrm{N} 66^{\circ} \mathrm{E}$ and a dip $85^{\circ}$ to the southwest (after Stauder and Bollinger [1966]).

first nodal plane with a dip angle of $82^{\circ} \mathrm{SE}$ and a strike $\mathrm{N} 60^{\circ} \mathrm{E}$, move the second nodal plane, and calculate the synthetic seismograms until a good fit between the synthetic and the observed seismograms is achieved. Before doing this, a brief inspection of the radiation pattern on the basis of Figure 7 of Kanamori [1970] which is reproduced in Figure 4 is useful. The depth and the propagation distance are different between Figure 4 and the present case. However, this difference is not very serious as long as Figure 4 is used as a guideline. We make the strike of the fault in Figure 4 parallel to the strike of the first nodal plane of $P$ waves $\left(\mathrm{N} 62^{\circ} \mathrm{E}\right)$. It is then evident that all the pure strike-slip sources (both vertical and $45^{\circ}$ ) are inadequate for this earthquake because the direction perpendicular to the fault is the node direction for the synthetic Rayleigh waves whereas it is the loop direction in the observed Rayleigh waves. On the other hand, the radiation patterns for the dip-slip sources can be reconciled with the observed radiation patterns; in particular, the $45^{\circ}$ dip-slip source seems most appropriate because the lobe direction differs $45^{\circ}$ between Love and Rayleigh waves. Further, from the amplitude ratio of Love to Rayleigh waves, the double-couple source may be preferable to the single-couple source.

On the basis of this reconnaissance, we start with a double-couple pure dip-slip with a dip angle of $82^{\circ}$ and dip direction of $\mathrm{S} 28^{\circ} \mathrm{E}$ (strike $\mathrm{N} 62^{\circ} \mathrm{E}$, see Figure $5 \mathrm{~B}$ ); one of the $P$-wave 


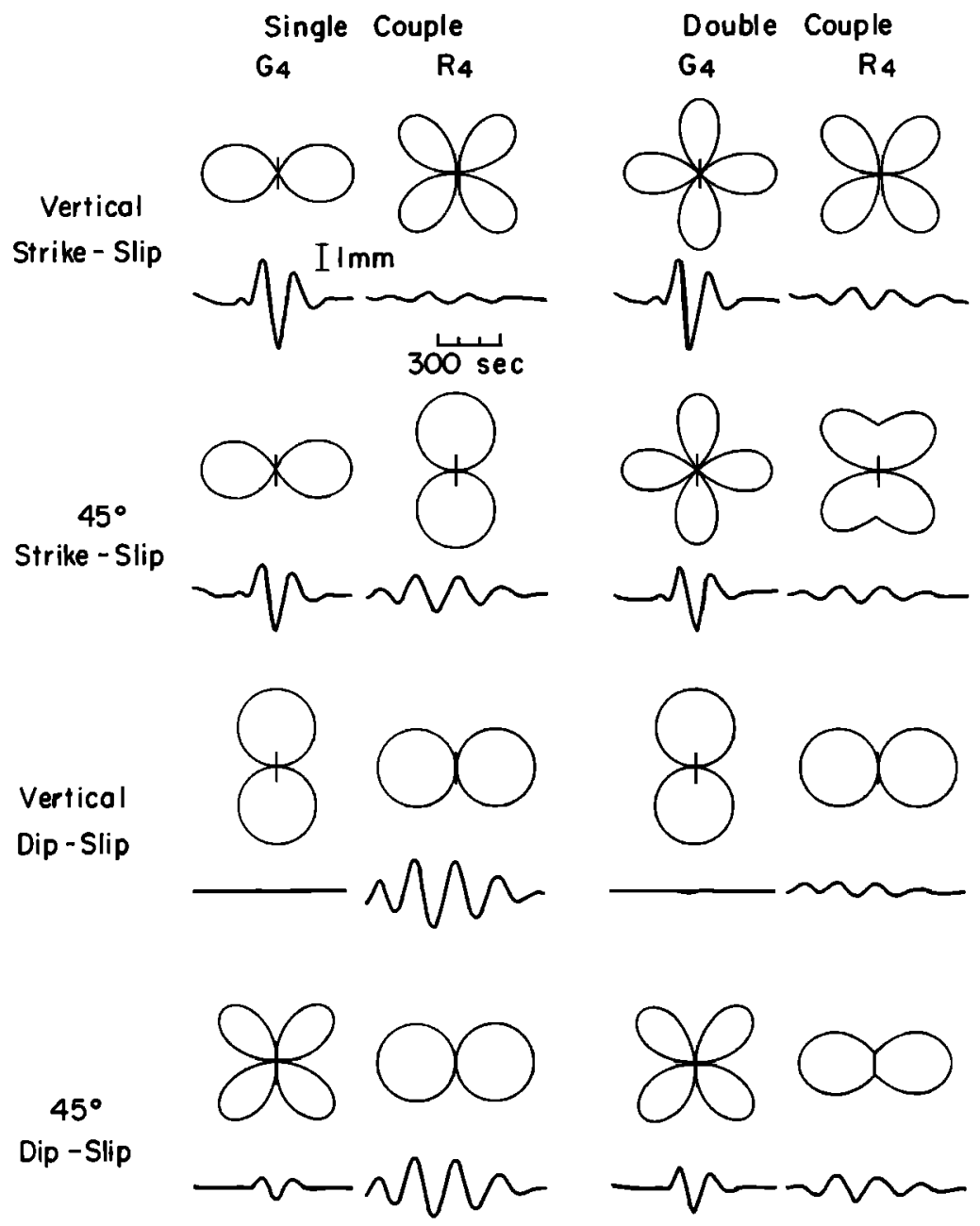

Fig. 4. Radiation patterns and wave forms in the direction of maximum amplitude of synthetic Love (G4) and Rayleigh (R4) waves for eight fundamental force geometries. The depth is $53 \mathrm{~km}$ (after Kanamori [1970]).

nodal planes for this model coincides with the observed nodal plane of $P$ waves; the other nodal plane has a dip angle of $8^{\circ}$ and dip direction of $\mathrm{N} 28^{\circ} \mathrm{W}$. The radiation pattern of synthetic seismograms computed for this model is shown in Figure 5B, where we see that the amplitude ratio of Love to Rayleigh waves is not consistent with the observations; the Rayleigh wave excitation relative to Love wave excitation is much larger than that observed. We found two ways of modifying this model so that it gives appropriate amplitude ratio of Love to Rayleigh waves. First, slight strike-slip component was superposed as shown in Figure
5C. Since Love waves are excited much more efficiently than Rayleigh waves by strike-slip sources, this model gives the right amplitude ratio. However, the surface-wave nodal lines are rotated with respect to the strike of the $P$-wave nodal planes. In order to obtain the best fit between the radiation patterns of synthetic and observed seismograms, a rotation of the fault planes by about $15^{\circ}$ is necessary. This, of course, alters the strike of the $P$-wave nodal planes but not to such an extent as to be incompatible with the observed data (see Figures 3 and $5 \mathrm{D}$ ). This model is designated model 1. 


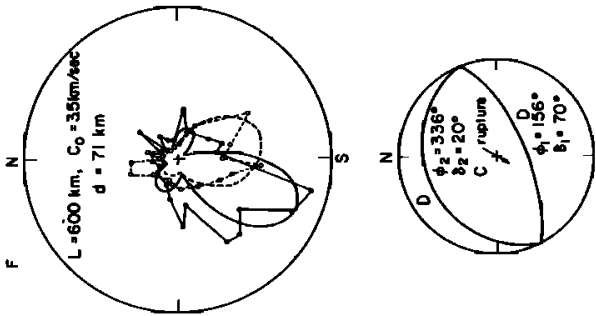

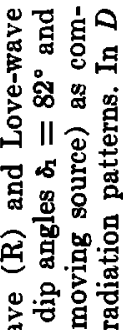
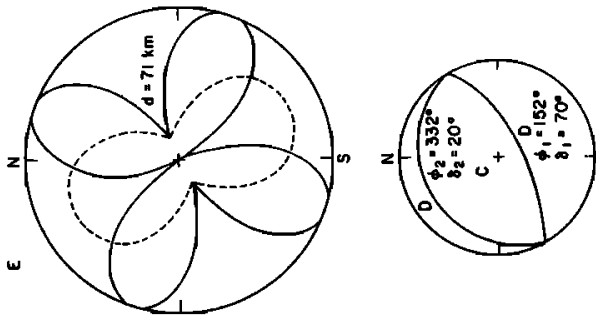
政

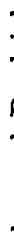

웡 证。 ค․ำ 樆 응 웅 $\checkmark$ 记范

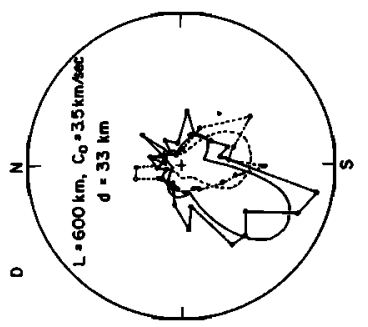

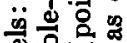

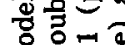
क 幽点寔 总 焉 究吅

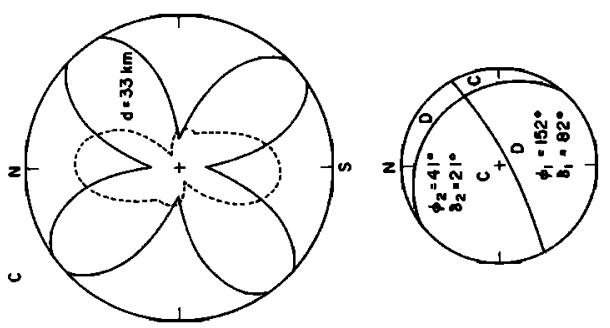

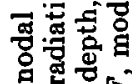
(1) 苍宁 녕 둔

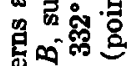
sin
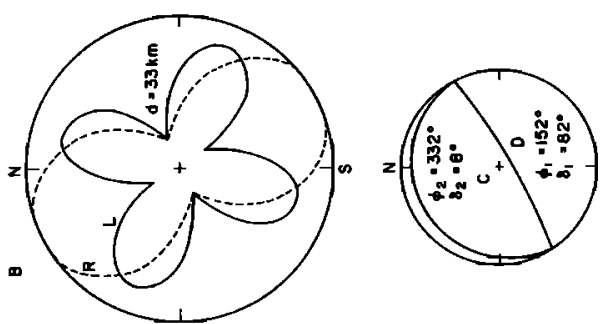

केष 을 웅 哥宠国和

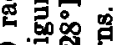

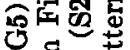
马영 क्ष 象焉 11.

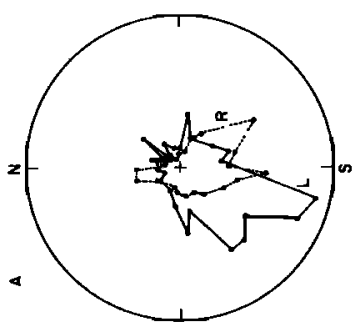

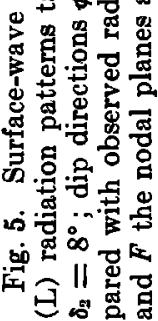


The second possible model is shown in Figure $5 \mathrm{E}$. The amplitude of Rayleigh waves of $100-$ to 200 -sec period decreases sharply as the focal depth increases from 0 to $100 \mathrm{~km}$. Thus, by increasing the depth from 33 to $71 \mathrm{~km}$, the amplitude ratio of Love to Rayleigh waves can be made consistent with the observed ratio. This depth, $71 \mathrm{~km}$, may seem incompatible with the depth of the main shock determined by the onset times of $P$ waves at teleseismic stations. However, the onset times of $P$ waves determine the location of the very beginning of the brittle fracture. It is possible that for such a great earthquake, the major fracture associated with the excitation of long-period surface waves involved a relatively large region extending to depths of $100 \mathrm{~km}$ or so. The depth $71 \mathrm{~km}$ should be considered as the average depth of the focal region. In the model given in Figure $5 \mathrm{E}$, the dip angles are also changed from $82^{\circ}$ to $70^{\circ}$, and from $8^{\circ}$ to $20^{\circ}$. These changes also contribute to bringing the amplitude ratio of Love to Rayleigh waves up to the right value. This model is called Model 2 and will be discussed later.

Asymmetry. The asymmetry can be explained by introducing a moving source. The direction of the rupture can be inferred from the asymmetry of the radiation pattern. Since the Rayleigh wave radiation pattern shows a large asymmetry in the direction perpendicular to the strike of the fault, the rupture velocity must have a horizontal component normal to the strike of the fault. On the other hand, for Love waves, the largest asymmetry occurs in the NE-SW direction suggesting that the rupture velocity has a component in this direction. From these observations we can constrain the direction of rupture in a fairly narrow range, $\mathrm{S} 20^{\circ} \mathrm{W}$ to $\mathrm{S} 30^{\circ} \mathrm{W}$. The rupture velocity and

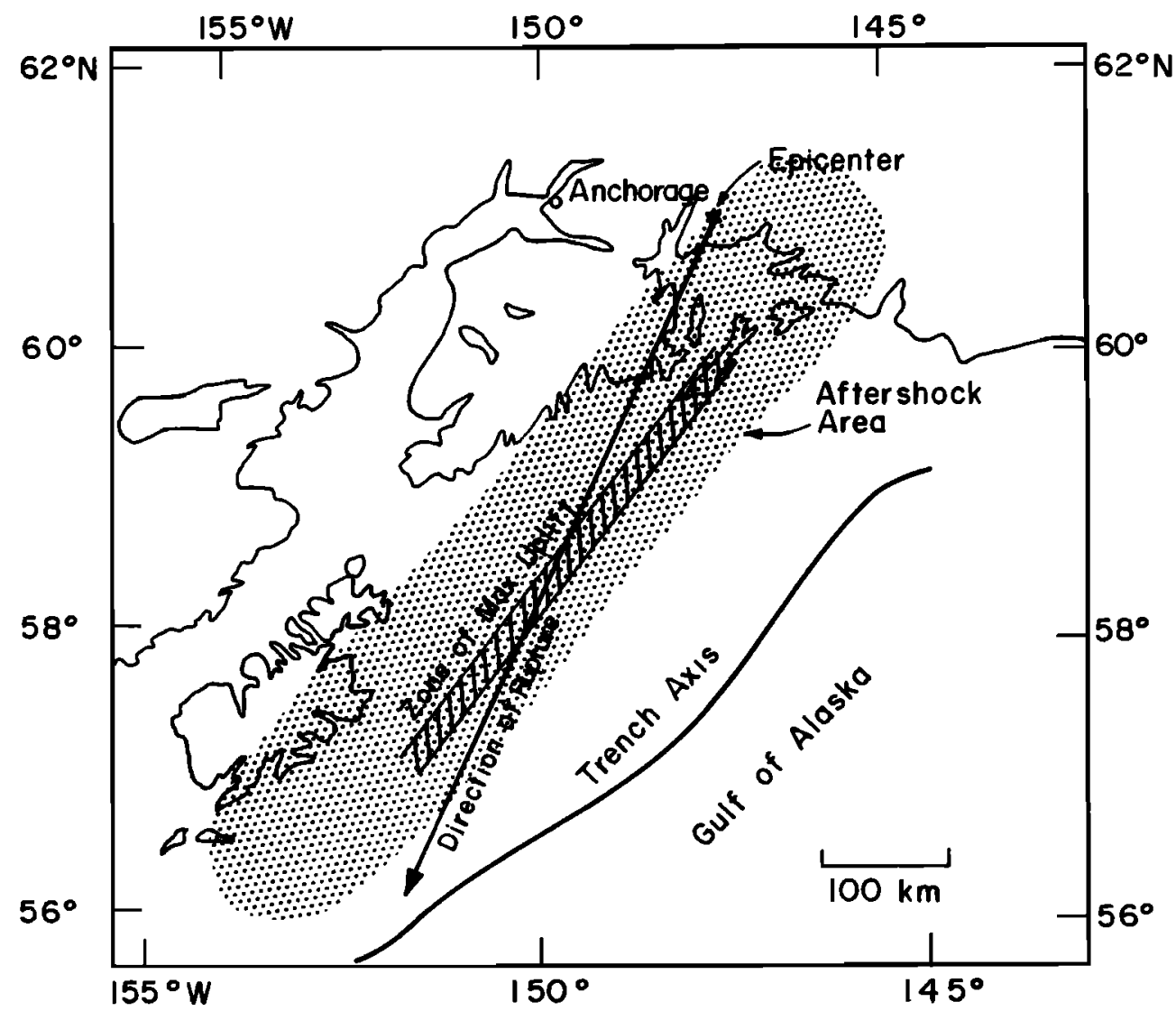

Fig. 6. Tectonic deformation (adopted from Plafker [1965]), aftershock area (adopted from Algermissen et al. [1969]), and the direction of rupture. 


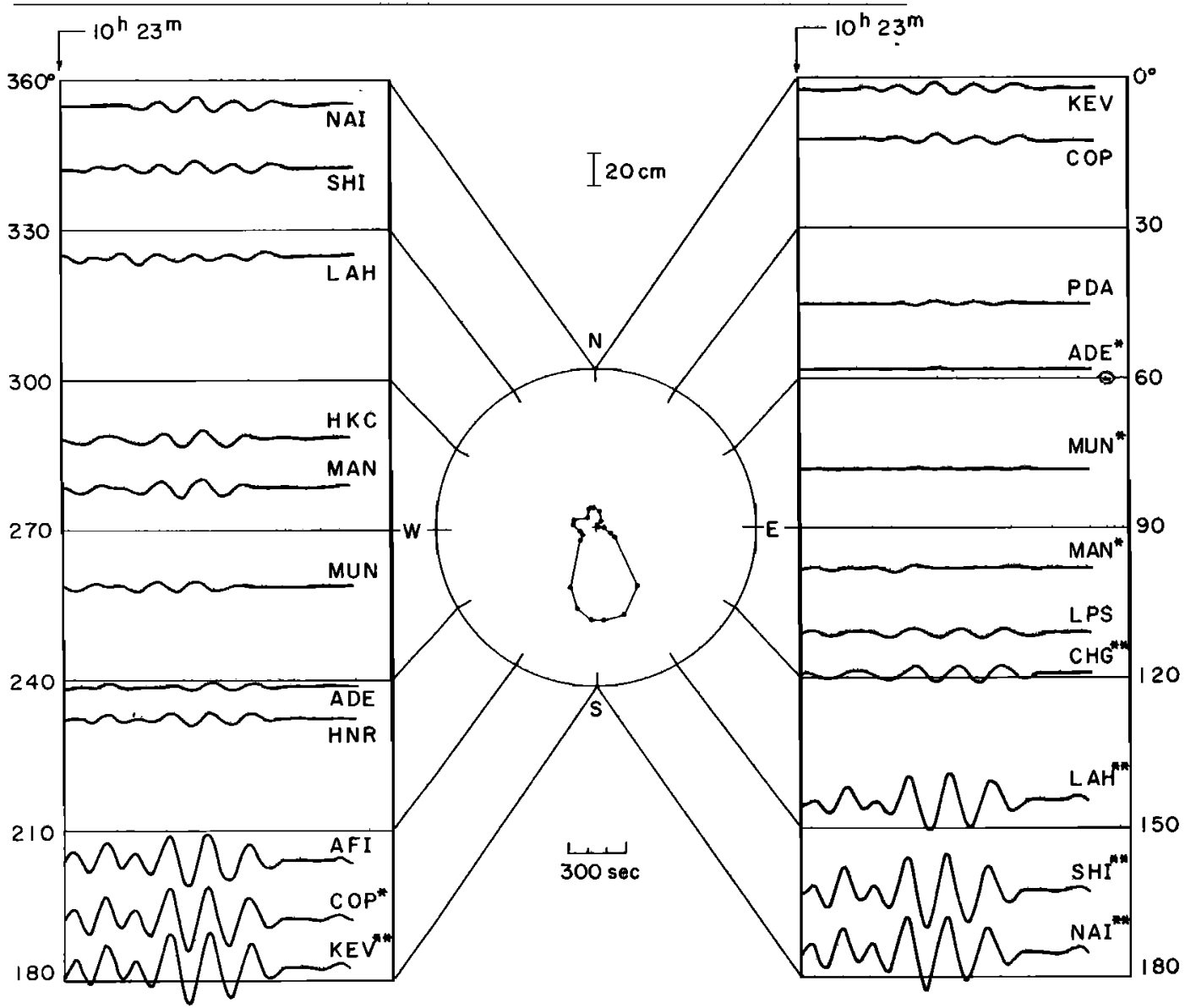

Fig. 7. Synthetic Rayleigh waves (R5 at $\Delta=9 \pi / 2$ ) for model 2: double-couple pure dip slip; fault plane dip, $20^{\circ}$; dip direction, $\mathrm{N}_{24}{ }^{\circ} \mathrm{W}$; rupture length, $600 \mathrm{~km}$; rupture velocity, $3.5 \mathrm{~km} / \mathrm{sec}$ toward $\mathrm{S} 25^{\circ} \mathrm{W}$; moment (time-function, step-function), $7.5 \times 10^{20}$ dyne-cm; depth, $71 \mathrm{~km}$. The vertical scale gives the trace amplitude on the standard 30-100 seismogram with a magnification of $\mathbf{1 5 0 0}$. Station names correspond to those in Figure 1.

the rupture length are difficult to determine independently [see Benioff et al., 1961; Kanamori, 1970] from observations over a limited frequency band: either rupture velocity or rupture length has to be somewhat restrained. If we take a rupture velocity of $3.5 \mathrm{~km} / \mathrm{sec}$, one of the representative values for major earthquakes [see Benioff et al., 1961; Press et al., 1961; Ben-Menahem and Toksöz, 1962; Kanamori, 1970], we find a rupture length of 600 $\mathrm{km}$ most appropriate, as shown in Figures $5 \mathrm{D}$ and $5 \mathrm{~F}$, where the effect of the moving source is superposed on the point-source radiation pattern. The method of computation is the same as that used by Kanamori [1970]. For rupture velocities of 2.5 and $4.5 \mathrm{~km} / \mathrm{sec}$, rupture lengths of 450 and $750 \mathrm{~km}$, respectively, are appropriate. Considering the extent of the tectonic deformation [Plafker, 1965] and the aftershock activity [Algermissen et al., 1969], the combination $(3.5 \mathrm{~km} / \mathrm{sec}, 600 \mathrm{~km})$ seems most appropriate (see Figure 6) and will be used hereafter. The rupture velocity and the rupture length obtained here are consistent with those obtained by Toksöz et al. [1965], allowing for the uncertainties mentioned above.

In Figures 5D and 5F, minor adjustments are made by slightly rotating the fault plane. The resulting $P$-wave nodal planes are not completely consistent with the observed first- 
motion data but are still tolerable (see Figure 3) considering that the fault motion associated with the excitation of long-period surface waves may be slightly different from that of $P$ waves.

As has been noted, the radiation pattern of Rayleigh waves has a large asymmetry in the direction normal to the strike of the steeply dipping nodal plane of $P$ waves. This observation precludes the possibility that the actual rupture took place on this plane; no rupture propagation on such a steep plane can produce such a large asymmetry in the direction per- pendicular to it. This leads to an important conclusion that the fault plane of this earthquake is the gently dipping plane, not the steep plane. Thus, in model 1 , the fault plane has a dip of $21^{\circ}$ toward $\mathrm{N} 26^{\circ} \mathrm{E}$, and the rupture propagates up-dip on this plane in the direction nearly perpendicular to its strike. One difficulty then arises. The rupture, after starting from a depth around $33 \mathrm{~km}$ or so, reaches the earth's surface when it propagates up-dip over a distance of about $100 \mathrm{~km}$. Thus at least six parallel fault planes, en echelon from NE to SW, are

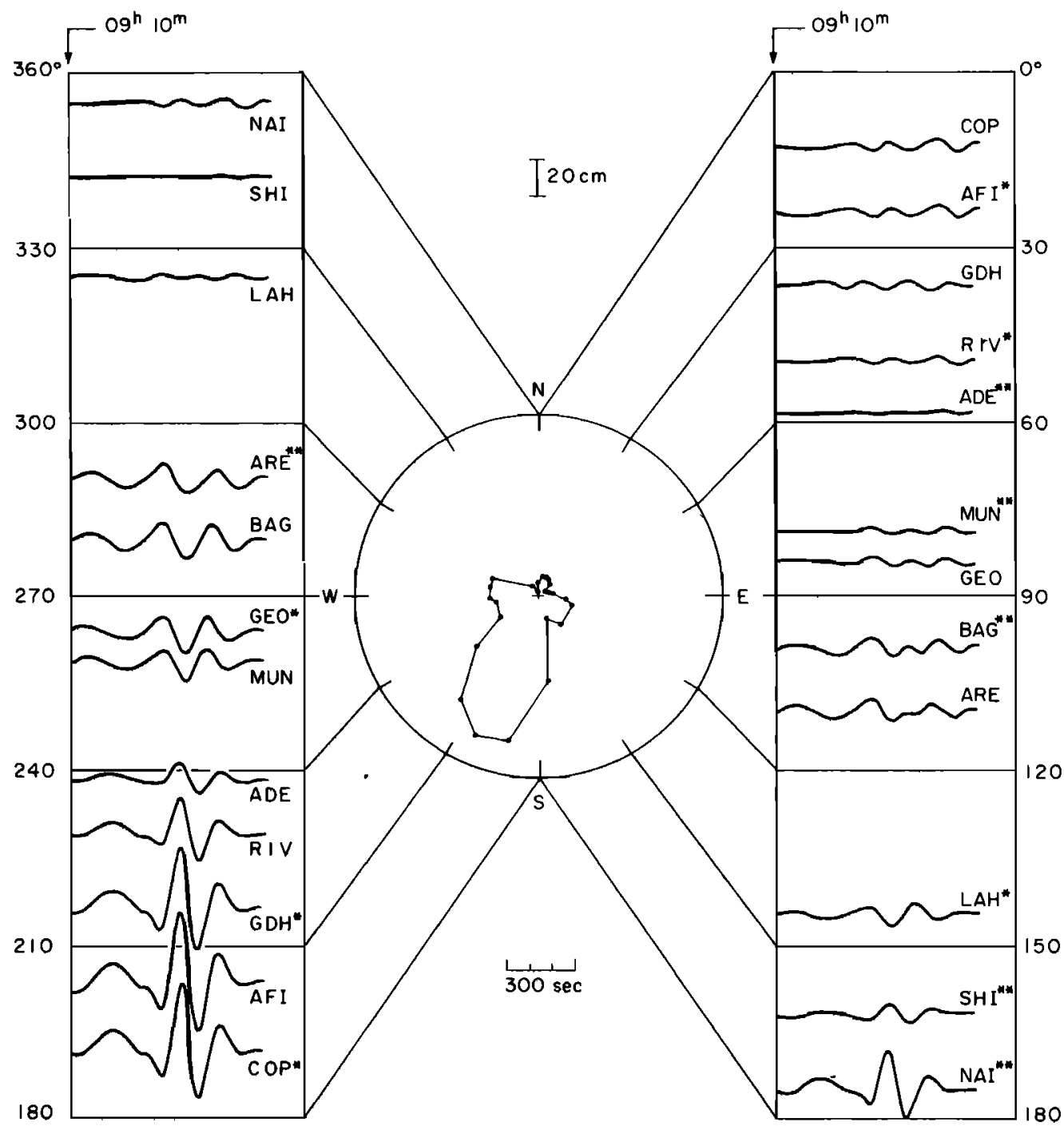

Fig. 8. Synthetic Love waves (G5 at $\Delta=9 \pi / 2$ ) for model 2. For explanations, see the legend of Figure 7 . 
necessary to represent the entire rupture length, $600 \mathrm{~km}$. This picture is somewhat artificial and physically implausible.

In model 2, on the other hand, the rupture starts from the NE end of the focal region and propagates, slightly up-dip, on a fault plane having a dip angle of $20^{\circ}$ and dip direction of $\mathrm{N} 24^{\circ} \mathrm{W}$; the direction of rupture propagation is more or less parallel to the strike of the fault so that the entire rupture process may take place on a single fault plane. This model is simpler and perhaps physically more plausible than model 1 . The faulting of model 2 is essentially a low-angle thrust fault, the oceanic block underthrusting beneath continent. This picture is generally similar to the one proposed by Plafker [1965], Savage and Hastie [1966], and Stauder and Bollinger [1966]. Because of its simplicity and plausibility we shall take model 2 as our final solution. From the direct comparison of the amplitude between synthetic and observed seismograms, the seismic moment can be estimated as $7.5 \times 10^{\circ}$ dyne-cm, the largest value ever reported.

For the overall comparison we computed synthetic seismograms G5 and R5 for model 2 at azimuths corresponding to those of the stations used here. The results are shown in Figures 7 and 8 . A remarkable similarity between Figures 1 and 7 , and between Figures 2 and 8 is found. At some of the stations (e.g., $\mathrm{COP}^{*}, \mathrm{GDH}^{*}$ for Love waves, COP* for Rayleigh waves), even the wave form and the phase agree very well. Since the equalized seismograms at these stations were derived from $\mathrm{R} 4$ and $\mathrm{G4}$, they are more reliable than those derived from R5, R6, G5, and G6.

\section{Discussion and Conclusions}

In the computations of the effect of the moving source, we ignored the change of the depth as the point source propagates. Although the change of the depth could be taken into account by changing the excitation functions in the computations of the synthetic seismograms as the depth changes, we did not think it worthwhile, considering the gross simplification made in modeling the moving source.

From the geometry of the fault plane and the rupture propagation, the lateral dimension of the focal region can be estimated at about 300 $\mathrm{km}$. To represent such a 'two-dimensional' fault, the one-dimensional rupture discussed above is clearly an oversimplified model. A more sophisticated two-dimensional rupture model as discussed by Hirasawa and Stauder [1965] may be more appropriate. We tried several two-dimensional rupture models according to Hirasawa and Stauder. However, we found that the radiation pattern is relatively insensitive to the rupture parameters in the lateral direction, and could not determine those parameters from the observed radiation patterns. We therefore consider that the one-dimensional rupture model introduced above represents those two-dimensional models that have an overall movement in $\mathrm{S} 25^{\circ} \mathrm{W}$ direction.

Wyss and Brune [1967] believe that this earthquake is a multiple shock consisting of at least six independent shocks greater than $m_{b}=6.6$ within $70 \mathrm{sec}$ after the onset of the earthquake. From the long-period surface waves, however, it is difficult to resolve these individual events; the present result neither supports nor rejects their conclusion.

This earthquake is probably the first earthquake that positively shows that the rupture propagation has appreciable component in the direction normal to the fault strike. This removes the otherwise inherent ambiguity in the selection of the fault plane out of the two $P$ wave nodal planes of double-couple dip-slip sources.

The uniqueness of the solution cannot be guaranteed fully. However, as we saw in the comparison between Figure 3 and Figures 1 and 2, only one out of the eight fundamental force geometries was found to be reasonably consistent with the data; it would be rather surprising if a force geometry that is simple yet entirely different from either model 1 or model 2 can be found to be consistent with the observed radiation patterns and the amplitude ratio of Love to Rayleigh waves.

Implicit in model 2 is the extension of the focal region to a relatively large depth, $100 \mathrm{~km}$ or so. At first this depth seems a little too large in the light of the depth of aftershock activity. Algermissen et al. [1969] and Page [1968] concluded that most of the aftershocks occurred within a depth of $40 \mathrm{~km}$. However, the local quadripartite and tripartite observations of micro-aftershocks [Hori et al., 1966; Aki et al., 1969; Matumoto and Page, 1969] did indicate 
considerable mantle activity. Although it is not clear whether this mantle activity is activated by the Alaska earthquake [Aki et al., 1969] or is due to a fluctuation of the background seismic activity in this region [Page, 1968], the present result seems to favor the former idea. It is possible that the faulting involves a considerable depth range, whereas the aftershock activity peaks at a relatively shallow depth.

The nature of the faulting of this earthquake is very similar to that of the Kurile Islands earthquake of 1963 [Kanamori, 1970] in that they are both low-angle thrust faultings. This is probably typical of island-arc earthquakes. The width of the fault plane, about $300 \mathrm{~km}$, is much larger than that of typical transcurrent or transform faults such as the San Andreas fault.

Following $A k i$ [1966], we can estimate from the observed moment the slip dislocation, stress drop, strain drop, and released strain energy using the slip dislocation theory of the faulting. We take the fault dimension as $500 \times 300 \mathrm{~km}^{2}$ (estimated from the geometry of the fault plane and the rupture propagation), and the rigidity, $0.7 \times 10^{19} \mathrm{dyne}^{-\mathrm{cm}^{-2}}$. The results are: average slip dislocation, 7 meters in $\mathrm{N} 24^{\circ} \mathrm{W}$ direction; stress drop, 28 bars; strain drop, $0.4 \times 10^{-4}$; released strain energy, $1.5 \times 10^{55}$ ergs. The displacement of 7 meters can be compared with the figure 10 meters, estimated from the tectonic deformation by Savage and Hastie [1966]. In view of the large difference in the time scale and the method, we consider the agreement reasonably good. This agreement suggests that the slip-dislocation model is adequate for representing earthquake source. The value of the seismic moment estimated here, $7.5 \times 10^{20}$ dyne-cm, is largest of all the values heretofore reported.

Acknowledgments. I am grateful to Drs. Keiiti Aki and Frank Press for kindly reading the manuscript and making many suggestions. In constructing the final model, I benefited from discussions with Drs. Keiiti Aki, Nafi Toksöz, and Tomowo Hirasawa.

This work was supported by the Air Force Office of Scientific Research under contract AF49 (638) 1632.

\section{REFERENCES}

Aki, K., Generation and propagation of $G$ waves from the Niigata earthquake of June 16, 1964,
2, Estimation of earthquake moment, released energy, and stress-strain drop from the $G$ wave spectrum, Bull. Earthquake Res. Inst. Tokyo Univ., 44, 73, 1966.

Aki, K., M. Hori, and H. Matumoto, Microaftershocks observed at a temporary array station on the Kenai Peninsula from May 19 to June 7, 1964, in The Prince William Sound, Alaska, Earthquake of 1964 and Aftershocks, vol. 2, edited by L. E. Leipold, pp. 131-156, U.S. Department of Commerce, Environmental Science Services Administration, Washington, D. C., 1969.

Algermissen, S. T., Mechanism of the Prince William Sound earthquake, in ESSA Symposium on Earthquake Prediction, pp. 20-25, U.S. Department of Commerce, Environmenta] Science Services Administration, Washington. D. C., 1966 .

Algermissen, S. T., W. A. Rinehart. R. W. Sherburne, and W. H. Dillinger, Jr., Preshocks and aftershocks of the Prince William Sound earthquake of March 28, 1964, in The Prince William Sound, Alaska, Earthquake of 1964 and Aftershocks, vol. 2, edited by I. E. Leipold, pp. 79130, US. Department of Commerce, Environmental Science Services Administration, Washington. D. C., 1969.

Benioff, H., F. Press, and S. Smith, Excitation of the free oscillations of the earth by earthquakes, J. Geophys. Res., 66, 605, 1961.

Ben-Menahem, A., and M. N. Toksöz. Source mechanism from spectra of long-period seismic surface waves, 1, The Mongolian earthquake of December 4, 1957, J. Geophys. Res., 67, 1943, 1962.

Harding, S. T.. and S. T. Algermissen, Focal mechanism of the Prince William Sound, Alaska earthquake of March 28, 1964, Bull. Seismol. Soc. Amer., 69, 799, 1969.

Hirasawa, T., and W. Stauder, On the seismic body waves from a finite moving source, Bull. Seismol. Soc. Amer., 55, 237, 1965.

Hori, M., H. Matumoto, and K. Aki, Observation of microaftershocks of the Alaska earthquake of March 28, 1964 (in Japanese), J. Seismol. Soc. Japan, 19, 187, 1966.

Kanamori, H., Synthesis of long-period surfacc waves and its application to earthquake source studies-Kurile Island earthquake of October $13,1963, J$. Geophys. Res., $75(26)$, this issue, 1970.

Matumoto, T., and R. A. Page, Jr., Microaftershocks following the Alaska earthquake of March 28, 1964: Determination of hypocenters and crustal velocities in the Kenai PeninsulaPrince William Sound area, in The Prince William Sound, Alaska, Earthquake of 1964 and Aftershocks, vol. 2, edited by L. E. Liepold, pp. 157-173, US. Department of Commerce, Environmental Science Services Administration, Washington, D. C., 1969.

Page, R., Aftershocks and microaftershocks of 
the great Alaska earthquake of 1964, Bull. Seismol. Soc. Amer., 68, 1131, 1968.

Plafker, G., Tectonic deformation associated with the 1964 Alaska earthquake, Science, 1/4, 1675, 1965.

Press, F., Displacements, strains, and tilts at teleseismic distances, J. Geophys. Res., 70, 2395, 1965.

Press, F., and D. Jackson, Alaskan earthquake, 27 March 1964: Vertical extent of faulting and elastic strain energy release, Science, 1/7, 867, 1965.

Press, F., A. Ben-Menahem, and M. N. Toksöz, Experimental determination of earthquake fault length and rupture velocity, J. Geophys. Res., 66, 3471, 1961.

Savage, J. C., and L. M. Hastie, Surface deformation associated with dip-slip faulting, J. Geophys. Res., $71,4897,1966$.

Sherburne, R. W., S. T. Algermissen, and S. T. Harding, The hypocenter, origin time, and mag- nitude of the Prince William Sound earthquake of March 28. 1964, in The Prince William Sound, Alaska, Earthquake of 1964 and Aftershocks, vol. 2, edited by L. E. Leipold, pp. 49 69, U.S. Department of Commerce, Environmental Science Services Administration, Washington, D. C., 1969.

Stauder, W., and G. A. Bollinger, The focal mechanism of the Alaska earthquake of March 28,1964 , and of its aftershock sequence, $J$. Geophys. Res., $71,5283,1966$.

Toksöz, M. N., A. Ben-Menahem, and D. G. Harkrider, Source mechanism of Alaska earthquake from long-period seismic surface waves (abstract), Trans. Amer. Geophys. Union, 46, 154, 1965.

Wyss, M., and J. Brune, The Alaska earthquake of 28 March 1964: A complex multiple rupture, Bull. Seismol. Soc. Amer., 57, 1017, 1967.

(Received March 30, 1970.) 